\title{
Pain, anxiety and patient satisfaction in office hysteroscopy, is there a link? Are patient satisfaction questionnaires reliable?
}

\author{
Antonio A. Paulo ${ }^{1,2}$, Antonio Pipa ${ }^{1}$, Claudia Raquel Andrade ${ }^{1}$, Raquel Oliveira ${ }^{3}$, \\ Vera M. Afreixo ${ }^{4}$
}

\author{
${ }^{1}$ Department of Obstetrics and Gynecology, Hospital Centre Tondela, Viseu, Portugal \\ ${ }^{2}$ Department of Health Sciences, University of Aveiro, Portugal \\ ${ }^{3}$ Psychologue accompagnante, Cabinet ESPAS-IDDEES, Paris, France \\ ${ }^{4}$ Institute of Biomedicine, University of Aveiro, Portugal
}

Received: 15 January 2016

Revised: 12 February 2016

Accepted: 17 February 2016

\section{*Correspondence: \\ Dr. Antonio A. Paulo, \\ E-mail: antoniosantospaulo@sapo.pt}

Copyright: (c) the author(s), publisher and licensee Medip Academy. This is an open-access article distributed under the terms of the Creative Commons Attribution Non-Commercial License, which permits unrestricted non-commercial use, distribution, and reproduction in any medium, provided the original work is properly cited.

\begin{abstract}
Background: Office hysteroscopy is becoming increasingly popular leading to examinations and operations without anesthesia. Anxiety is always present before an aversive medical intervention and may play a role in pain perception. The objectives of the study were to determine if pain perception is linked to anxiety and how well patient satisfaction questionnaires correlate with pain.

Methods: Prospective observational study enrolled one hundred and four women. One hundred cases were included and analyzed. Patients scheduled for office hysteroscopy, who accepted to participate and were able to answer questionnaires.

Results: A ten centimeter visual analogue scale was used for pain evaluation and the State anxiety-trait inventory for adults questionnaires for anxiety assessment. Three other satisfaction questionnaires, each consisting of three answers, were also administered and investigated. Analysis was performed using SPSS 22.0 IBM for windows software tools.

Conclusions: Correlation between anxiety and pain reporting showed no influence with anxiety trait ( $\mathrm{p}$ value = 0.4170 ) and a mild correlation with anxiety state ( $p$ value $=0.146$ ). Classification of pain into "no pain", "mild pain", "moderate pain" and "severe pain", should be revised in office hysteroscopy: for visual analogue scale, scores of 2.5 to $3 \mathrm{~cm}$ correspond to the lower boundary of moderate pain and scores above limit $6.5 \mathrm{~cm}$ should define pain as severe. Satisfaction questionnaires significantly correlated to discomfort ( $\mathrm{p}$ value $<0.001$ ) and may be a practical option to assess tolerance of medical procedures with excellent sensibility and specificity.
\end{abstract}

Keywords: Office hysteroscopy, Anxiety, Pain, Satisfaction questionnaires

\section{INTRODUCTION}

In 1967 Fritz Menken used a pediatric cystoscope to examine the womb. ${ }^{1}$ Hysteroscopy is nowadays a routine technique, allowing direct visualization and diagnosis and is considered gold standard in uterine abnormal bleeding. ${ }^{2-10}$
Office hysteroscopy $(\mathrm{OH})$ is becoming increasingly popular, leading to examinations and even operations without anesthesia, as modern mini-hysteroscopes avoid cervical dilation, misoprostol administration facilitates operations and the vaginoscopic "no-touch" approach improves tolerance. ${ }^{11-13}$ 
Anxiety is almost always present before an aversive medical intervention and may play a role in pain perception. ${ }^{14-18}$ There seems to be a positive association between anxiety level and visual analog scale (VAS) pain reporting, and in some cases nervousness may lead to catastrophizing (exaggerated negative orientation toward pain stimuli). ${ }^{17,18}$ Pain can be predicted with a measure of catastrophizing one week prior to scheduled appointment for procedure. ${ }^{19}$

The State anxiety-trait inventory for adults (STAI) Form Y1 (administered for anxiety trait) and Form Y2 (administered for anxiety state) have been validated for evaluation and scoring of anxiety. ${ }^{20,21}$ Both consist of a self-administered twenty question sheet with four possible answers (not at all, somewhat, moderately so and very much so). Score values range from twenty to a maximum of eighty in each subscale. In general the higher the score, the more anxious the patient is and it has been suggested that scores of thirty-nine to forty in young adults, and fifty-four to fifty-five in older adults are indicative of clinically significant anxiety. ${ }^{21,22}$ There are Portuguese versions of these questionnaires which have been validated. ${ }^{23}$

$\mathrm{OH}$ patients may have higher VAS scores with longer waiting time and women with higher STAI scores may experience more pain or indeed there may not be any correlation between STAI and VAS scores. ${ }^{24-26}$ Distractions such as music may be associated with lower pain and anxiety. ${ }^{27}$

As to patient satisfaction questionnaires, how well do they correlate with pain score? De Iaco wrote "one-third of women experienced severe pain, although most (83\%) claimed they were willing to have a repeat procedure under the same conditions". ${ }^{28}$

There are two questions we will try to answer: Is pain perception linked to anxiety? And how well do patient satisfaction questionnaires correlate with pain score?

\section{METHODS}

From March to June 2015, one hundred and eighteen patients scheduled for $\mathrm{OH}$ at centro hospitalar tondelaviseu, Portugal were invited to enroll in this prospective observational study. Of theses one hundred and four accepted to participate but four cases had incomplete data and were excluded. One hundred cases were included and analyzed. The study was conducted in compliance with the protocol, the declaration of Helsinki, the good epidemiological practice, and all applicable laws and regulations. This work was supported by Portuguese iBiMED - Institute for Biomedicine and the Portuguese Foundation for Science and Technology (FCT-Fundacao para a Ciencia e a Tecnologia) within projects: UID/BIM/04501/2013

\section{Inclusion criteria}

All women with scheduled $\mathrm{OH}$ were considered candidates. Only those who accepted to participate, had no acute infection, were not pregnant and had sufficient understanding of Portuguese reading and writing to be able to answer questionnaires were included. They were fully informed that whether they chose or not to participate, procedure would be the same. All others were excluded (Figure 1).

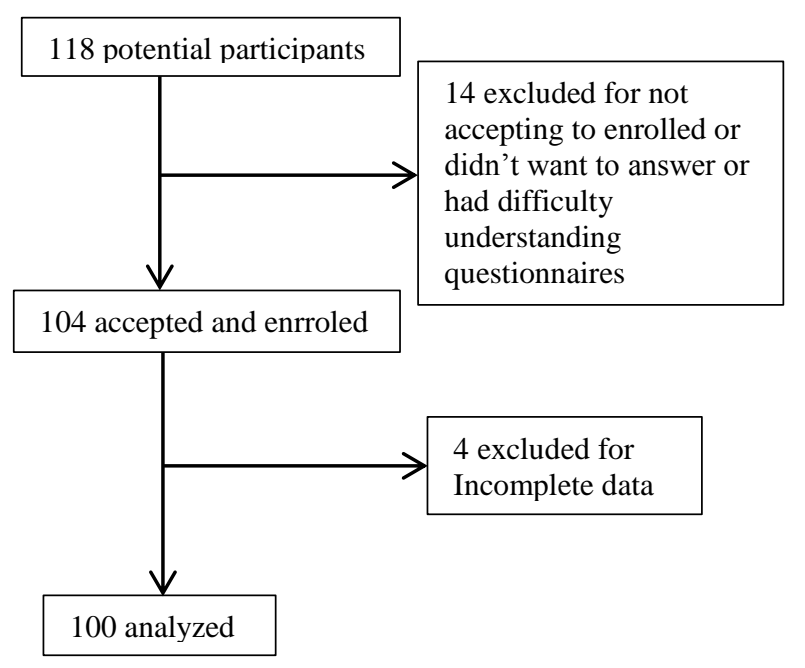

Figure 1: Flow diagram of selection of women.

Before examination, a STAI Y1 and a STAI Y2 (www.mindgarden.com) questionnaire was offered to participants, with a thorough explanation of how to answer, stressing replies were confidential, couldn't be traced to patient by unauthorized personnel and should be as honest as possible. Population characteristics are described on Table 1.

Table 1: Population characteristics.

\begin{tabular}{|llll|ll|}
\hline Age & $\begin{array}{l}\text { No0 } \\
\text { Mini- }\end{array}$ & $\begin{array}{l}\text { Maxi- } \\
\text { mum }\end{array}$ & Mean & SE \\
\hline Gesta & & 28 & 84 & 54.61 & 13.296 \\
\hline Body weight & & 0 & 9 & 2.19 & 1.376 \\
\hline Height & & 145 & 179 & 159.13 & 6.447 \\
\hline C-section & 21 & 0 & 3 & 0.33 & 0.697 \\
\hline Nuligest & 9 & & & & \\
\hline Parous & 91 & & & & \\
\hline Menopause* & 55 & & & & \\
\hline Fertile & 45 & & & \\
\hline
\end{tabular}

${ }^{*}$ Last menses more than twelve months and woman not on hormone therapy 
Table 2: Reason for hysteroscopy.

\begin{tabular}{|lll|}
\multirow{5}{*}{ Valid } & Menorrhagia & Frequency \\
\cline { 2 - 3 } & Post-menopausal bleeding & 19 \\
\cline { 2 - 3 } & Thick endometrium & 15 \\
\cline { 2 - 3 } & Sterility & 63 \\
\cline { 2 - 3 } & Total & 3 \\
\hline
\end{tabular}

Women were referred to hysteroscopy to study common gynecological conditions: menorrhagia, post-menopausal bleeding, sonographic thick endometrium and sterility (Table 2).

Hysteroscopy was performed using the vaginal no touch approach with a $3.5 \mathrm{~mm}$ outer sheet device $(2.9 \mathrm{~mm}$ optics either from Fiegert Endotech ${ }^{\circledR}$ Tuttlingen, Germany or Karl Storz Hopkins ${ }^{\circledR}$ Tuttlingen, Germany) with a fore oblique $30^{\circ}$ mini-hysteroscopy. An Ackermann ${ }^{\circledR}$ xenon light source and a constant flow Richard Wolf $₫$ hystero pump, using saline at eighty mm of mercury was standard in procedure. A $3 \mathrm{CCD}$ endocam ${ }^{\circledR}$ enable vision on a screen. Misoprostol had been prescribed to be applied intra-vaginal the previous night.

At the end of procedure a nurse would show the woman a ruler having on the side facing the patient a straight 10 $\mathrm{cm}$ line with markings "no pain" (left end) and "maximal pain" (on the right end). A sliding courser was freely placed by the patient over the line matching to her pain experience. At the back the ruler was graded in millimeters allowing healthcare personnel (nurse) to read results of patient scoring. Authors chose to value centimeters and only whole numbers were taken into account (e.g. 0 to $9 \mathrm{~mm}$ score zero, 1 to $1.9 \mathrm{~mm}$ scored one and so forth). Total duration of procedure did not exceed five minutes.

After scoring patient's VAS, each women was asked to answer three satisfaction questions: Procedure was easy? (With three possibilities "easy", "some discomfort" or "hard to endure"); second question pain medication (with three possibilities "very important to have medication", "important to have medication" or "not important to have medication") and a third question would you take medication next time? (With three possibilities "no", "don't know" or "would take").

Statistical analysis was performed with SPSS 22.0 IBM for windows and in a statistical hypothesis test with a $\mathrm{p}$ value $<0.05$ the effect was considered significant. The confidence intervals are consequently reported with a 95\% assurance level. The normal goodness of fit testing was applied for all quantitative variables. KolmogorovSmirnov test revealed that for almost all quantitative variables the normal distribution fit is rejected. In accordance we performed non parametric statistical tests. For details please refer to annex table at the end of this article. Kruskal Wallis test was used to evaluate the association between the pain score and the satisfaction variables, Spearman's correlation was used to correlate anxiety and pain, and finally receiver operating characteristic (ROC curve) were constructed with answers from satisfaction questionnaires in order to establish cutoff points.

\section{RESULTS}

Hysteroscopy was complete in ninety three cases and failed in seven. Those failures were rescheduled for the same procedure a few weeks later. Four cases were not successful at this second attempt and were then scheduled to hysteroscopy under anesthesia. All cases were analysed irrespective of completion of procedure and pain score results refer to the first attempt at hysteroscopy.

Hysteroscopy findings are as shown in Table 3 and include normal cavity, polyp, endometrial hyperplasia, carcinoma, uterine septum and submucosal and intramural mioma.

Table 3: Hysteroscopic diagnosis.

\begin{tabular}{|lll|}
\hline & & Frequency \\
\cline { 2 - 3 } & Normal cavity & 35 \\
\cline { 2 - 3 } Volyp & 45 \\
\cline { 2 - 3 } & Hyperplasia & 1 \\
\cline { 2 - 3 } & Carcinoma & 4 \\
\cline { 2 - 3 } & Septum & 1 \\
\cline { 2 - 3 } & Mioma & 7 \\
\cline { 2 - 3 } & Incomplete visualization & 7 \\
\cline { 2 - 3 } & Total & 100 \\
\hline
\end{tabular}

Mean pain and STAI scores are shown on Table 4, showing percentiles and maximum and minimum values.

Table 4: Pain and anxiety scores.

\begin{tabular}{|c|c|c|c|c|}
\hline & \multicolumn{2}{|c|}{$\begin{array}{c}\text { Mean } \\
\text { pain score }\end{array}$} & STAI-Y1 & STAI-Y2 \\
\hline $\mathrm{N}$ & Valid & 100 & 100 & 99 \\
\hline Minimum & 0 & 21 & 20 & Minimum \\
\hline Maximum & 10 & 69 & 73 & Maximum \\
\hline Percentiles & 25 & 2.25 & 36.00 & 36.00 \\
\hline & 50 & 4.50 & 45.50 & 43.00 \\
\hline & 75 & 7.00 & 52.00 & 49.00 \\
\hline
\end{tabular}
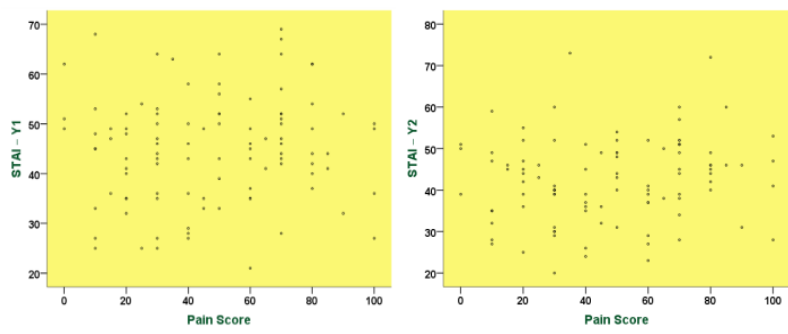

Figure 2: Scatter plot pain score versus anxiety score. 
The association between variables was evaluate by Spearman's correlation. There seems to be a weak correlation between anxiety and pain score which is not significant ( $\mathrm{p}$ value>0.05): $8 \%$ correlation between pain score and STAI Y1 and 15\% for STAI Y2 (Table 5). Scatter plots visually express this lack of correlation and so probably anxiety is not a significant factor in pain perception (Figure 2).

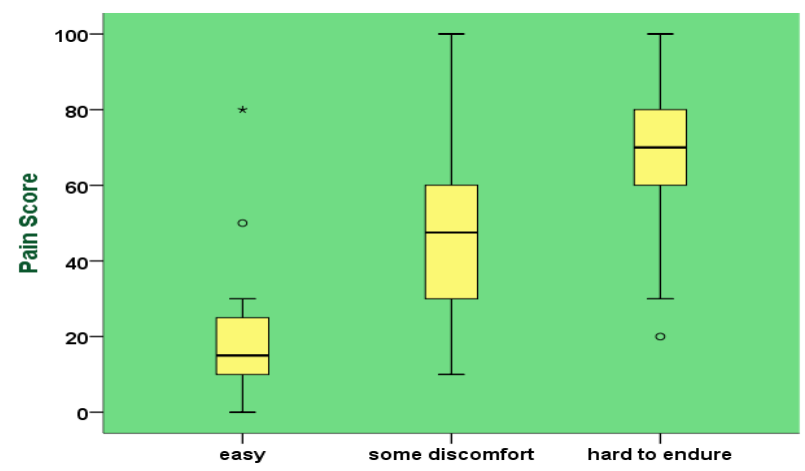

Figure 3: Procedure was easy?

Table 5: Procedure was easy?

\begin{tabular}{|llll|}
\hline \multicolumn{4}{|c|}{ Test statistics } \\
\hline & Pain Score & STAI - Y1 & STAI - Y2 \\
\hline Chi-Square & 45.625 & 2.568 & 7.513 \\
\hline Asymp. Sig. & 0.000 & 0.277 & 0.023 \\
\hline a. Kruskal Wallis test & \\
\hline b. Grouping variable: Procedure was easy \\
\hline
\end{tabular}

The Kruskal Wallis test was used to evaluate the association between the pain score and the satisfaction variables (three questions shown in Figures 3, 4 and 5 coupled with STAI scores results). Once again, anxiety scores do not show significant results ( $\mathrm{p}$ value $>0.05$ ) except for question number one and for the Y2 questionnaire (state anxiety) which showed a modest association between anxiety and pain ( $p$ value $=0,023$ ) as shown in Figure 3.

In contrast, this same Kruskal Wallis test shows significant association between pain score and replies from satisfaction questionnaires $(p<001)$. The boxplot below each statistical test show patients answers to be significant and consistent. The higher the pain score, the more likely women will complain and will be willing to accept medication for pain relief (Figures 5, 6 and 7).

Table 6: Pain and medication.

\begin{tabular}{|c|c|c|c|}
\hline \multicolumn{4}{|c|}{ Test statistics ${ }^{\mathrm{a}, \mathrm{b}}$} \\
\hline & Pain Score & STAI - Y1 & STAI - Y2 \\
\hline Chi-Square & 27.416 & 1.038 & 2.933 \\
\hline Asymp. Sig. & 0.000 & 0.595 & 0.231 \\
\hline \multicolumn{4}{|c|}{ a. Kruskal Wallis test } \\
\hline \multicolumn{4}{|c|}{ b. Grouping variable: Pain medication } \\
\hline
\end{tabular}

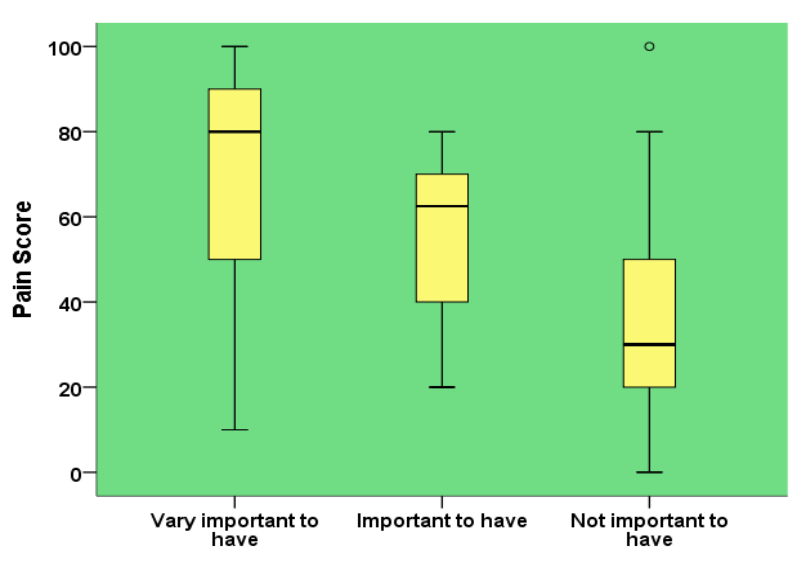

Figure 4: Pain and medication.

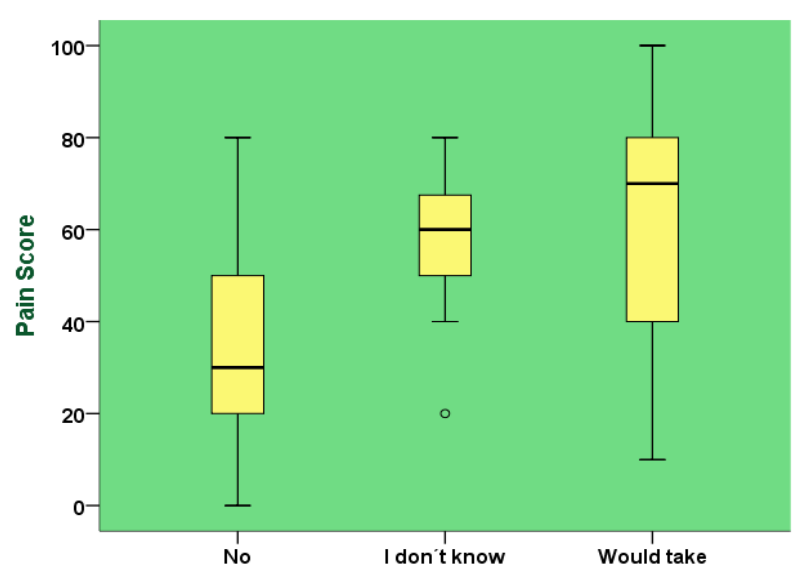

Figure 5: Would you take medication next time?

Table 7: Would you take medication next time?

\begin{tabular}{|c|c|c|c|}
\hline \multicolumn{4}{|c|}{ Test statistics ${ }^{\mathrm{a}, \mathrm{b}}$} \\
\hline & Pain Score & STAI - Y1 & STAI - Y2 \\
\hline Chi-Square & 18.353 & 0.915 & 0.086 \\
\hline Asymp. Sig. & 0.000 & 0.633 & 0.958 \\
\hline \multicolumn{4}{|c|}{ a. Kruskal Wallis test } \\
\hline \multicolumn{4}{|c|}{$\begin{array}{l}\text { b. Grouping variable: Would you take medication next } \\
\text { time? }\end{array}$} \\
\hline
\end{tabular}

We further explored the satisfaction questionnaires trying to understand how well they fitted to pain score and if some estimate regarding pain perception could be made from these simple answers. Replies were broken down to binary responses for analysis. First we considered "easy versus not easy" (this latter group aggregating some discomfort and hard to endure responses) giving a total of twenty two for "easy" versus seventy eight for "not easy". A second set of binary responses was considered involving "tolerable" (joining up easy and some discomfort groups) versus "hard to endure" giving a total of twenty nine for "tolerable" and seventy one for "hard to endure". 
Table 8: ROC curve for pain score: easy (not painful) procedures.

\begin{tabular}{|c|c|c|c|c|}
\hline \multicolumn{5}{|c|}{ Area under the curve } \\
\hline \multicolumn{5}{|c|}{ Test result variable(s): Pain score } \\
\hline \multirow{2}{*}{ Area } & \multirow{2}{*}{$\begin{array}{l}\text { Std. } \\
\text { Error }^{\mathrm{a}}\end{array}$} & \multirow{2}{*}{$\begin{array}{l}\text { Asymptotic } \\
\text { Sig. }\end{array}$} & \multicolumn{2}{|c|}{$\begin{array}{l}\text { Asymptotic } 95 \% \\
\text { confidence interval }\end{array}$} \\
\hline & & & $\begin{array}{l}\text { Lower } \\
\text { bound }\end{array}$ & $\begin{array}{l}\text { Upper } \\
\text { bound }\end{array}$ \\
\hline 0.905 & 0.044 & 0.000 & 0.819 & 0.990 \\
\hline \multicolumn{5}{|c|}{$\begin{array}{l}\text { The test result variable(s): Pain score has at least one } \\
\text { tie between the positive actual state group and the } \\
\text { negative actual state group. Statistics may be biased. }\end{array}$} \\
\hline \multicolumn{5}{|c|}{ a. Under the nonparametric assumption } \\
\hline \multicolumn{5}{|c|}{ b. Null hypothesis: true area $=0.5$} \\
\hline
\end{tabular}

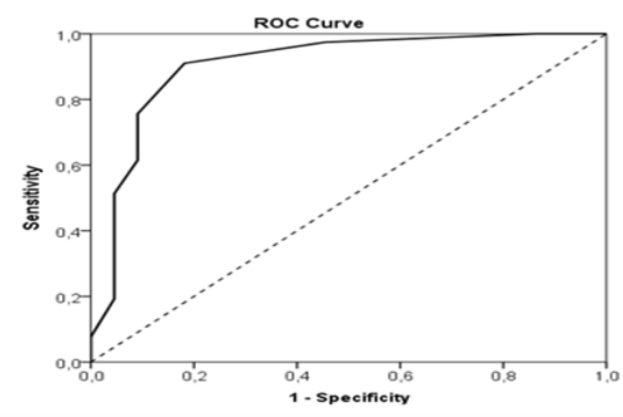

Figure 6: ROC curve for pain score: easy (not painful) procedures.
These responses allowed a ROC curve to be constructed from theses binary responses to identify procedures as easy and hard to endure (Figures 6 and 7). From the ROC curve we calculated a Yoden index (=sensitivity+specificity-1) and for each plot a cutoff point was attained. In Table 11 see the cutoffs matching to the maximum Yoden index values highlighted in yellow. Testing of the area under a ROC curve was conducted and the statistical results were significant $(\mathrm{p}$ value $<0.001)$.

Table 9: ROC curve for pain score for hard to endure (painful) procedures.

\section{Area under the curve}

Test result variable(s): Pain score

\begin{tabular}{|c|c|c|c|c|}
\hline \multirow{2}{*}{ Area } & \multirow{2}{*}{$\begin{array}{l}\text { Std. } \\
\text { Error }^{\mathrm{a}}\end{array}$} & \multirow{2}{*}{$\begin{array}{l}\text { Asymptotic } \\
\text { Sig. }\end{array}$} & \multicolumn{2}{|c|}{$\begin{array}{l}\text { Asymptotic } 95 \% \\
\text { confidence interval }\end{array}$} \\
\hline & & & $\begin{array}{l}\text { Lower } \\
\text { bound }\end{array}$ & $\begin{array}{l}\text { Upper } \\
\text { bound }\end{array}$ \\
\hline 0.831 & 0.045 & 0.000 & 0.742 & 0.920 \\
\hline \multicolumn{5}{|c|}{$\begin{array}{l}\text { The test result variable(s): Pain score has at least one } \\
\text { tie between the positive actual state group and the } \\
\text { negative actual state group. Statistics may be biased. }\end{array}$} \\
\hline \multicolumn{5}{|c|}{ a. Under the nonparametric assumption } \\
\hline \multicolumn{5}{|c|}{ b. Null hypothesis: true area $=0.5$} \\
\hline
\end{tabular}

Table 10: Yoden index constructed from ROC curve.

\begin{tabular}{|c|c|c|c|c|c|c|c|}
\hline \multicolumn{8}{|c|}{ Coordinates of the Curve (from curve in Figure 6) } \\
\hline $\begin{array}{l}\text { Test Result } \\
\text { Variable (s): }\end{array}$ & Pain Score & & & $\begin{array}{l}\text { Test Result } \\
\text { Variable (s): }\end{array}$ & in Score & & \\
\hline $\begin{array}{l}\text { Positive if greater } \\
\text { than or equal to }\end{array}$ & Sensitivity & $\begin{array}{l}1- \\
\text { Specificity }\end{array}$ & $\begin{array}{l}\text { Yoden } \\
\text { index }\end{array}$ & $\begin{array}{l}\text { Positive if Greater } \\
\text { Than or Equal To }\end{array}$ & Sensitivity & $\begin{array}{c}1 \text { - } \\
\text { Specificity }\end{array}$ & $\begin{array}{l}\text { Yoden } \\
\text { index }\end{array}$ \\
\hline-1.00 & 1.000 & 1.000 & 0.000 & -1.00 & 1.000 & 1.000 & 0.000 \\
\hline 0.50 & 1.000 & 0.864 & 0.136 & 0.50 & 1.000 & 0.958 & 0.042 \\
\hline 1.50 & 0.974 & 0.455 & 0.520 & 1.50 & 1.000 & 0.803 & 0.197 \\
\hline 2.50 & 0.910 & 0.182 & 0.728 & 2.50 & 0.966 & 0.662 & 0.304 \\
\hline 3.50 & 0.756 & 0.091 & 0.666 & 3.50 & 0.862 & 0.507 & 0.355 \\
\hline 4.50 & 0.615 & 0.091 & 0.524 & 4.50 & 0.828 & 0.366 & 0.461 \\
\hline 5.50 & 0.513 & 0.045 & 0.467 & 5.50 & 0.793 & 0.254 & 0.540 \\
\hline 6.50 & 0.372 & 0.045 & 0.326 & 6.50 & 0.690 & 0.141 & 0.549 \\
\hline 7.50 & 0.192 & 0.045 & 0.147 & 7.50 & 0.414 & 0.056 & 0.357 \\
\hline 8.50 & 0.077 & 0.000 & 0.077 & 8.50 & 0.172 & 0.014 & 0.158 \\
\hline 9.50 & 0.051 & 0.000 & 0.051 & 9.50 & 0.103 & 0.014 & 0.089 \\
\hline 11.00 & 0.000 & 0.000 & 0.000 & 11.00 & 0.000 & 0.000 & 0.000 \\
\hline
\end{tabular}

The test result variable(s): Pain Score has at least one tie between the positive actual state group and the negative actual state group.

a. The smallest cutoff value is the minimum observed test value minus 1 , and the largest cutoff value is the maximum observed test value plus 1 . All the other cutoff values are the averages of two consecutive ordered observed test values. Test variable is "pain score" and State variable is question "procedure was easy" dichotomized as: easy vs not easy 


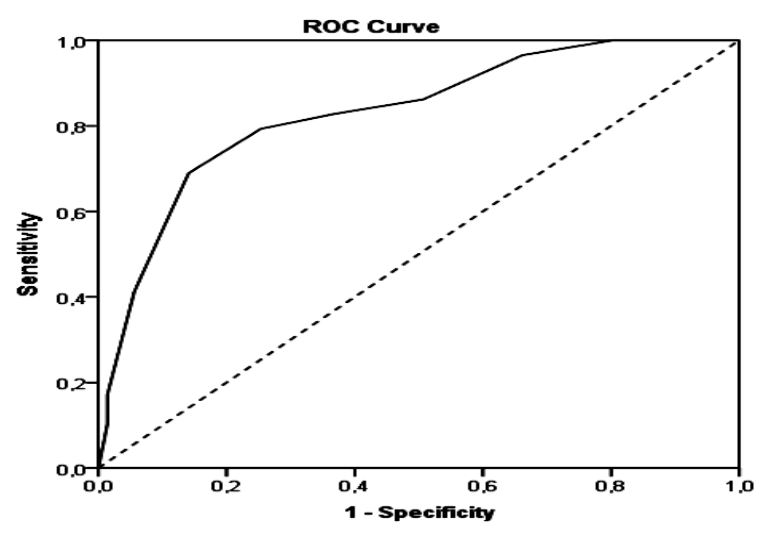

Figure 7: ROC curve for pain score for hard to endure (painful) procedures.

Table 11: Two by two cross-tabulation for procedure difficulty vs pain.

\begin{tabular}{|lllll|}
\hline \multirow{2}{*}{ Easy versus not easy (discomfort + hard to endure) } \\
\hline \multirow{2}{*}{ VAain } & \multicolumn{2}{l}{ Procedure was } & \multicolumn{2}{l|}{ Total } \\
\cline { 2 - 5 } & Easy & \multicolumn{2}{l|}{ Not easy } \\
\hline \multirow{2}{*}{ Total } & $(0,2)$ & 18 & 7 & 25 \\
\cline { 2 - 5 } & $(3,10)$ & 4 & 71 & 75 \\
\hline
\end{tabular}

The best cutoff points matched VAS 2.5 and VAS 6.5 for answer shifts, and we split results into categories "easy" (zero to two) "some discomfort" (three to six) and "hard to endure" (seven to ten).

We then used a two by two cross-tabulation for the first question "procedure was easy" (with three possible answers: "easy", "some discomfort" or "hard to endure"). Replies analysed were easy versus not easy (which included "some discomfort" and "hard to endure"). We were able to then calculate sensitivity (94\%) and specificity $(72 \%)$ in predicting that hysteroscopy (when answers were "not easy" to tolerate) would correspond to VAS score above two (Table 11).

\section{DISCUSSION}

Angioli used music and found a positive distracting effect lowering pain in OH surgery and STAI Y1 post-operative scores compared with operation without music. ${ }^{27}$ Carta on the other hand found waiting time (along with age and menopause) to be associated with increased pain but no increase in anxiety was found. ${ }^{25}$ Gupta stated women in hysteroscopy outpatient units experience higher levels of anxiety than other patients in gynecology care. ${ }^{26}$ Kokanali also found a positive correlation between waiting time and anxiety with increased pain scores. ${ }^{24}$

Our data do not support a correlation between STAI form Y1 (trait anxiety) and an increased pain score. As to
STAY form Y2 (state anxiety), data showed a very modest correlation between state anxiety and pain.

We did however, find a significant correlation between satisfaction questionnaires and women's discomfort $(\mathrm{p}<001)$ and all three questions are consistent in responses.

\section{Interpretation (findings in light of other evidence)}

To the best of our knowledge this is the first study comparing satisfaction questionnaire answers to pain scoring and finding statistical significance in this comparison.

We find it quite significant that women tend to consider "easy" or acceptable, maneuvers with VAS scores up to approximately three centimeters. This cutoff has been considered the upper limit score for "mild" pain. ${ }^{29-33}$ Not all authors agree: Jensen and Burckhardt suggest a higher cutoff of 4.4 centimeters. Our data suggest this threshold proposed by Jensen to be somewhat high and a VAS around three seems more acceptable and adequate for clinical evaluation of pain perception in $\mathrm{OH}^{34,35}$

Use of simple questionnaires is reproductive and reliable and may help grade nociceptive experience into acceptable or unacceptable.

\section{CONCLUSION}

In our study, we did not find an association between anxiety and pain scores in women undergoing $\mathrm{OH}$. Nevertheless our first satisfaction variable had significance with STAI-Y2 $(\mathrm{p}=0.023)$, although effect was weak (Figure 3 ). This may imply state anxiety may very slightly influence pain.

Our data also recommends classification of pain into "no pain", "mild pain", "moderate pain" and "severe pain", should be revised in $\mathrm{OH}$. Contrary to Jensen and Burckhardt our figures supports that for VAS evaluation, scores of 2.5 to $3 \mathrm{~cm}$ correspond the lower boundary of moderate pain and scores above the upper limit of VAS $6.5 \mathrm{~cm}$ should define pain as severe.

Questionnaires on patient satisfaction may be useful and are reliable. They reflect closely patient nociceptive experience. Evaluation of acceptance of an unpleasant medical intervention with a three answer questionnaire accurately reflects nociceptive experience compared to VAS evaluation. These three answer questions are simple and more practical to use than VAS scoring. Three answer questionnaire objectively asking women about tolerability may be accurate, easy to use and give healthcare providers an alternative useful tool for assessing patient discomfort, when performing aversive medical interventions. Sensibility and specificity are both excellent for theses inquiries. 


\section{ACKNOWLEDGEMENTS}

Authors wish to thank nurses Catarina Mota, Carla Santos and Sandra Coelho for their dedication and cooperation in this study, helping with pain scoring and explaining questionnaires.

\section{Funding: No funding sources}

Conflict of interest: None declared

Ethical approval: The study was approved by the Institutional Ethics Committee

\section{REFERENCES}

1. Campo R, Van Belle Y, Rombauts L, Brosens I, Gordts S. Office mini-hysteroscopy. Hum Reprod Update. 1999;5(1):73-81.

2. Fatemi HM, Kasius JC, Timmermans A, van Disseldorp J, Fauser BC, Devroey P. Prevalence of unsuspected uterine cavity abnormalities diagnosed by office hysteroscopy prior to in vitro fertilization. Hum Reprod. 2010;25(8):1959-65.

3. Ergenoglu M, Yeniel AO, Yildirim N, Akdemir A, Yucebilgin S. Recurrent uterine rupture after hysterescopic resection of the uterine septum. Int $\mathbf{J}$ Surg Case Rep. 2013;4(2):182-4.

4. Buchanan EM, Weinstein LC, Hillson C Endometrial cancer. Am Fam Physician. 2009;80(10):1075-80.

5. Clark TJ, Barton PM, Coomarasamy A, Gupta JK, Khan KS. Investigating postmenopausal bleeding for endometrial cancer: cost-effectiveness of initial diagnostic strategies. BJOG. 2006;113(5):502-10.

6. Van Dongen H, De Kroon CD, Van den Tillaart SA, Louwe LA, Trimbos-Kemper GC, Jansen FW. A randomised comparison of vaginoscopic office hysteroscopy and saline infusion sonography: a patient compliance study. BJOG. 2008;115(10):1232-7.

7. Guin G, Sandhu SK, Lele A, Khare S. Hysteroscopy in evaluation of abnormal uterine bleeding. J Obstet Gynaecol India. 2011;61(5):546-9.

8. Guruwadayarhalli B, Jones SE, Srinivasan V. Hysteroscopy in the diagnosis of postmenopausal bleeding. Menopause Int. 2007;13(3):132-4.

9. Lee DO, Jung MH, Kim HY. Prospective comparison of biopsy results from curettage and hysteroscopy in postmenopausal uterine bleeding. J Obstet Gynaecol Res. 2011;37(10):1423-6.

10. Pal L, Lapensee L, Toth TL, Isaacson KB. Comparison of office hysteroscopy, transvaginal ultrasonography and endometrial biopsy in evaluation of abnormal uterine bleeding. JSLS. 1997;1(2):125-30.

11. Garbin O, Kutnahorsky R, Gollner JL, Vayssiere C. Vaginoscopic versus conventional approaches to outpatient diagnostic hysteroscopy: a two-centre randomized prospective study. Hum Reprod. 2006;21(11):2996-3000.
12. Siristatidis C, Chrelias C, Salamalekis G, Kassanos D. Office hysteroscopy: current trends and potential applications: a critical review. Arch Gynecol Obstet. 2010;282(4):383-8.

13. Cooper NA, Smith P, Khan KS, Clark TJ. Vaginoscopic approach to outpatient hysteroscopy: a systematic review of the effect on pain. BJOG. 2010;117(5):532-9.

14. Marteau TM, Walker P, Giles J, Smail M. Anxieties in women undergoing colposcopy. $\mathrm{Br} \mathrm{J}$ Obstet Gynaecol. 1990;97(9):859-61.

15. Kola S, Walsh JC. Determinants of pre-procedural state anxiety and negative affect in first-time colposcopy patients: implications for intervention. Eur J Cancer Care (Engl). 2012;21(4):469-76.

16. Walsh JC, Curtis R, Mylotte M. Anxiety levels in women attending a colposcopy clinic: a randomised trial of an educational intervention using video colposcopy. Patient Educ Couns. 2004;55(2):247-51.

17. Sullivan MJ, Stanish W, Waite H, Sullivan M, Tripp DA. Catastrophizing, pain, and disability in patients with soft-tissue injuries. Pain. 1998;77(3):253-60.

18. Baser E, Togrul C, Ozgu E, Esercan A, Caglar M, Gungor T. Effect of pre-procedural state-trait anxiety on pain perception and discomfort in women undergoing colposcopy for cervical cytological abnormalities. Asian Pac J Cancer Prev. 2013;14(7):4053-6.

19. Sullivan M. Gender Differences in Pain and Pain Behavior: The Role of Catastrophizing. Cognitive Therapy and Research. 2000;24(1):14.

20. Spielberger CD. STATE-TRAIT ANXIETY INVENTORY. In: Craighead IBWaWE, editor. The Corsini Encyclopedia of Psychology: John Wiley \& Sons, Inc. 2009.

21. Julian LJ. Measures of anxiety: state-trait anxiety inventory (stai), beck anxiety inventory (bai), and hospital anxiety and depression scale-anxiety (hadsa). arthritis care res (Hoboken). 2011;63(11):S46772 .

22. Kvaal K, Laake K, Engedal K. Psychometric properties of the state part of the Spielberger StateTrait Anxiety Inventory (STAI) in geriatric patients. Int J Geriatr Psychiatry. 2001;16(10):980-6.

23. Rodrigues C. Validação do teste TSAI-Y de Spielberger: avaliação da ansiedade face aos testes. psicologiacompt. 2009.

24. Kokanali MK, Cavkaytar S, Guzel AI, Topcu HO, Eroglu E, Aksakal O. Impact of preprocedural anxiety levels on pain perception in patients undergoing office hysteroscopy. J Chin Med Assoc. 2014;77(9):477-81.

25. Carta G, Palermo P, Marinangeli F, Piroli A, Necozione S, De Lellis V. Waiting time and pain during office hysteroscopy. J Minim Invasive Gynecol. 2012;19(3):360-4.

26. Gupta JK, Clark TJ, More S. Pattison H. Patient anxiety and experiences associated with an outpatient one-stop, see and treat hysteroscopy clinic. Surg Endosc. 2004;18(7):1099-104. 
27. Angioli R, De Cicco Nardone C, Plotti F, Cafa EV, Dugo N, Damiani P. Use of music to reduce anxiety during office hysteroscopy: prospective randomized trial. J Minim Invasive Gynecol. 2014;21(3):454-9.

28. De Iaco P, Marabini A, Stefanetti M, Del Vecchio C, Bovicelli L. Acceptability and pain of outpatient hysteroscopy. J Am Assoc Gynecol Laparosc. 2000;7(1):71-5.

29. Downie WW, Leatham PA, Rhind VM, Wright V, Branco JA, Anderson JA. Studies with pain rating scales. Ann Rheum Dis. 1978;37(4):378-81.

30. Program VIHA EoL. principles of pain Assessment. 2008. Available from: http://www.viha.ca/ NR/rdonlyres/FB1E3BDD-2D23-4C53-A4D30F9D2DCE1081/0/PrinciplesOfPainAssessment.pdf.

31. Toolkit SWRWC. WHO Pain Ladder with Pain Management Guidelines 2010. Available from: www.who.int/cancer/palliative/painladder/en/.

32. Taddio A, O'Brien L, Ipp M, Stephens D, Goldbach M, Koren G. Reliability and validity of observer ratings of pain using the visual analog scale (VAS) in infants undergoing immunization injections. Pain. 2009; 147(1-3):141-6.

33. Breivik H, Borchgrevink PC, Allen SM, Rosseland LA, Romundstad L, Hals EK. Assessment of pain. Br J Anaesth. 2008;101(1):17-24.

34. Jensen MP, Chen C, Brugger AM. Interpretation of visual analog scale ratings and change scores: a reanalysis of two clinical trials of postoperative pain. J Pain. 2003;4(7):407-14.

35. Burckhardt CS, Jones KD. Adult measures of pain: The McGill Pain Questionnaire (MPQ), Rheumatoid Arthritis Pain Scale (RAPS), Short-Form McGill Pain Questionnaire (SF-MPQ), Verbal Descriptive Scale (VDS), Visual Analog Scale (VAS), and West Haven-Yale Multidisciplinary Pain Inventory (WHYMPI). Arthritis \& Rheumatism. 2003;49(S5):S96-S104.

Cite this article as: Paulo AA, Pipa A, Andrade CR, Oliveira R, Afreixo VM. Pain, anxiety and patient satisfaction in office hysteroscopy, is there a link? Are patient satisfaction questionnaires reliable? Int $\mathbf{J}$ Reprod Contracept Obstet Gynecol 2016;5:642-50. 
Annex table.

\begin{tabular}{|c|c|c|c|}
\hline & \multicolumn{3}{|c|}{ Kolmogorov-Smirnov ${ }^{a}$} \\
\hline & Statistic & df & Sig. \\
\hline Age & 0.066 & 100 & $0.200^{*}$ \\
\hline Age at menopause & 0.137 & 55 & 0.012 \\
\hline Gesta & 0.235 & 100 & 0.000 \\
\hline Vaginal deliveries & 0.187 & 100 & 0.000 \\
\hline C-section & 0.472 & 100 & 0.000 \\
\hline Body weight & 0.106 & 100 & 0.008 \\
\hline Height & 0.096 & 100 & 0.023 \\
\hline $\begin{array}{l}\text { Diastolic blood pressure } \\
\text { (before) } \mathrm{mm} \mathrm{HG}\end{array}$ & 0.071 & 100 & $0.200^{*}$ \\
\hline $\begin{array}{l}\text { Systolic blood pressure } \\
\text { (before) } \mathrm{mm} \mathrm{HG}\end{array}$ & 0.050 & 100 & $0.200^{*}$ \\
\hline $\begin{array}{l}\text { Diastolic blood pressure } \\
\text { (after) } \mathrm{mm} \mathrm{HG}\end{array}$ & 0.090 & 100 & 0.043 \\
\hline $\begin{array}{l}\text { Systolic blood pressure } \\
\text { (after) } \mathrm{mm} \mathrm{HG}\end{array}$ & 0.071 & 100 & $0.200^{*}$ \\
\hline Oximetry before (\% O2) & 0.486 & 100 & 0.000 \\
\hline Oximetry after (\% O2) & 0.486 & 100 & 0.000 \\
\hline pulse (before) (BMP) & 0.084 & 100 & 0.078 \\
\hline pulse (after) (BMP) & 0.097 & 100 & 0.020 \\
\hline Body mass index & 0.120 & 100 & 0.001 \\
\hline
\end{tabular}

* This is a lower bound of the true significance. 